\title{
Sustainable Furniture that Grows with End-Users
}

\author{
Tim Bosch, Karin Verploegen, Stefan N. Grösser and Gu van Rhijn
}

\begin{abstract}
Economically and environmentally it might be more responsible or even feasible to combine products and services to elongate product lifetime. Gispen, a major office furniture producer in the Netherlands, has embraced circular economic principles to create new business, extend product life time and improve the adaptability of their products. In the Use-it-Wisely (UIW) project two applications were developed. To estimate possible business impacts of adapting a circular economy concept for a company, a dynamic business model simulation has been created by using the system dynamics methodology. And second, Gispen has developed a new Circular Economy Design Framework to support circular product design development. A combination of basic principles to design, upgrade, and reuse products according to circular economy principles are included in the framework as well as a circular life cycle assessment methodology. The development process, non-confidential company results of the tool application and directions for future research are described in this chapter.
\end{abstract}

Keywords Circular economy • Business models • Life Cycle Analysis • System dynamics

T. Bosch $(\bowtie) \cdot$ G. van Rhijn

Department Sustainable Productivity \& Employability, TNO, Leiden, Netherlands

e-mail: tim.bosch@tno.nl

G. van Rhijn

e-mail: gu.vanrhijn@tno.nl

K. Verploegen

Gispen, Culemborg, Netherlands

e-mail: karin.verploegen@gispen.nl

S.N. Grösser

Institute for Corporate Development, Bern University of Applied Sciences, Bern, Switzerland e-mail: stefan.groesser@bfh.ch 


\section{Introduction to the Company Challenge}

The market for office interior design is changing. In the last decade, costs, efficiency, quality, and design were the main drivers for office manufacturers. Nowadays, new market demands and government legislations have an impact on business. Customers have become more environmentally conscious, and the global market for environmental friendly goods and services is estimated at $€ 4.2$ trillion (Department for Business, Innovations and Skills 2012). By that, manufacturers of office furniture have to show and prove the circularity of design and manufacturing (e.g., end of life options, sources of material, and sustainability of suppliers). Furthermore, future government legislations require European manufacturers in many industries to assume responsibility for their products after use either for disposal or for reuse, and encourage them to incorporate as many recyclable materials as possible in their products to reduce waste (Communication from the Commission to the European Parliament 2015).

Besides the increased awareness on environmental issues, the market demand is fluctuating and has become more unpredictable, and strongly declined in recent years due to its sensitivity to the economic conjuncture. After a peak in 2007, total industry production has decreased by more than $14 \%$ and total sector employment decreased by $20 \%$ between 2007 and 2011 (CEPS 2014). Moreover, the market for office interior and furniture has moved closer towards a commodity market with the consequence to strongly compete on prices. Prices and margins have dropped significantly over the past decade. Office furniture has become a substitution good, i.e., multiple goods satisfy the same consumer need and therefore can be replaced by one another and tend to be influenced by cross-elasticity of demand, even though the acquisition value of furniture is still fairly high. Nowadays, employees of most companies work at all sorts of locations and new technological developments effect the way of working dramatically (e.g., virtual meetings, tablets). Moreover, new flexible, customized, and innovative office concepts are required to support the new generation of employees in the best possible way (Vos and Van der Voordt 2002; Vink et al. 2012). Office furniture should be more adaptable to future customer demands, i.e., the furniture should be able to handle better the changes in requirements for functionality, look and feel and numbers, but still guarantee a high level of quality and at a reasonable price. Proved sustainability, flexibility, and upgrades will become crucial elements to office furniture companies to guarantee long-term success. This leads to shorter lifecycles of office furniture due to changing demands on functionality.

Gispen, a major office furniture producer in the Netherlands, is aware of these changes and wants to overcome highly competitive dynamics in the current Dutch furniture market, in a lesser degree in the European market, by developing new product-service combinations (see company profile). Innovative product-service combinations prolong the life cycle time of an asset and thereby avoiding a new purchase incentive. Gispen especially focusses on the innovation of products and services based on circular economy principles (Ellen MacArthur Foundation 2013). Currently, most products in the field of office interior are designed, produced, and 
sold to the end-user. In case of malfunction, out of fashion, or changing requirements of the end-user, a new product is designed, produced, and sold again. The circular economy concept aims to keep products, components, and materials at their highest utility and value at all times (Ellen MacArthur Foundation 2013; McKinsey 2011). In contrast to a traditional linear economy, i.e., "take-make-dispose", the circular economy emphasizes reusability of products and raw materials as a starting point and minimize waste in the entire industrial and ecological system. Careful consideration of product design and materialisation may result in longer use of materials. Designing new adaptable and upgradable products is crucial in realizing this circular economy-based new business model.

To implement new product service combinations, aimed at implementing innovations and therefore elongating a products life, a sound business model should be developed. Currently, a strong interaction between Gispen and the customer during the sales and implementation stage (i.e., <1 year) takes place. However, office furniture will commonly be used for more than 10 years and hardly any interaction with customers occurs. Hence, it is currently almost impossible to directly perceive change in customer requirements, and thus benefits of upgrades or lifespan expansion cannot be reaped. In a new, alternative business model, Gispen wants to strengthen the relationship with the customer by more frequent interactions. Only then, Gispen could directly perceive changes in customer needs and consequently adapt or upgrade the products to meet these needs.

Next to product design and an appropriate business model, other crucial elements are, among others, organizing new closed-loop processes such as reverse logistics (Savaskan et al. 2004) or remanufacturing (Allwood et al. 2011). Remanufacturing will be one of the processes to close the loop and restore worn-out products to new-like condition and sometimes superior in performance and expected lifetime to the original new product. The total value of sold remanufactured goods as a share of total sales of all products within the furniture sector was estimated $1.3 \%$ in the US (USITC 2012). The Dutch report 'Remanufacturing HTSM' indicated that the market size of remanufacturing in the furniture industry in the Netherlands could be estimated at 50 million Euro (Innovatie Zuid 2013).

This chapter describes the developments at Gispen to close the gap: changing from a linear into a circular concept with a special focus on circular economy oriented alternative business models and circular product design. We have selected two methods from the Use-it-Wisely (UIW) platform. First, to estimate possible business impacts of adapting a circular economy concept for a company, a dynamic business model simulation is developed. We use the system dynamics methodology (Groesser, Chapter "Complexity Management and System Dynamics Thinking” of this book) to develop this analysis. The development process, as well as non-confidential company results, are described in Sect. 2.1. And second, Gispen has developed a new design Circular Economy Design Framework to support circular product development. Basic principles to design, upgrade, and reuse products according to circular economy principles are included in the framework (Van Rhijn, Chapter "Fostering a Community of Practice for Industrial Processes" and Pajula, Chapter "Virtual Reality and 3D Imaging to Support Collaborative 
Decision Making for Adaptation of Long-Life Assets" in this book). Section 2.2 explains this design framework. Section 3 concludes this chapter and provides avenues for future work.

Company Profile Gispen The Gispen Group BV is the second largest office furnisher and designer in The Benelux. Gispen was awarded the greenest company in the Netherlands in 2011 and has a long tradition of working environment friendly, i.e., from 2008 the EMAS certificate (verified environmental management). Gispens' mission statement-Be at your best - is put to practice by Gispens' core values: Sustainability, Innovation, Inspiration, and Design. Gispen as a designer, manufacturer and supplier creates ideal environments that have a positive impact on people. This combination provides all the ingredients needed for a sustainable approach through design, manufacturing principles and taking responsibility for a closed-loop system. Hence, the core value sustainability is increasingly important. In everything Gispen designs and produces they wish to make a positive contribution to the environment in which people live and work. In 2014, 21,000 products collected for repurpose and almost 1800 products have been refurbished, upgraded and brought back into use (sold) by Gispen. Having tools to make sustainable choices and to provide detailed, well-founded information to the end user assuring the necessary accountability has been the motivation to develop the models and tools described in this chapter (Fig. 1).
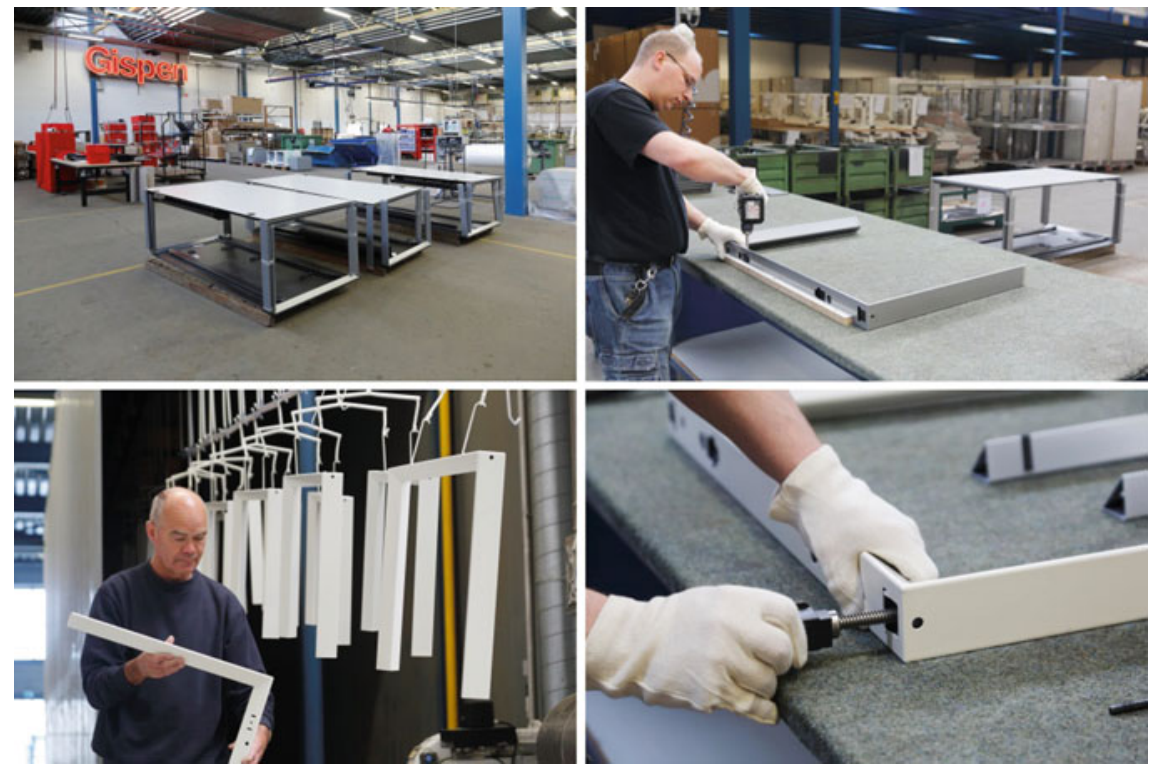

Fig. 1 Collecting, disassembly, remanufacturing and reassembling of office furniture at Gispens manufacturing site in Culemborg, The Netherlands 


\section{Detailed Application of the Tools and Solutions to the Company Challenges}

To tackle the company challenges as detailed in the introduction, various tools and methods are needed. In the UIW-project the following applications were developed to achieve the goals of Gispen:

- A System Dynamic (SD) simulation model. The SD model provides detailed insights into the dynamics of the changing business model. The business model will change from a single transaction model (sale/buy) to a (circular) product-service model. Hence, we develop a multiple transaction model with split payments.

- A Circular Economy Design Framework. In order to create awareness among customers and engineers and be able to rank product designs, a Design Framework, including a checklist has been developed. A circular Life Cycle Assessment (LCA) methodology is also part of this framework.

The process of developing these tools is a valuable undertaking by itself. This development requires attention, involvement of key personnel, and disciplines as well as intensive discussions amongst various company disciplines. Awareness and gaining acceptance for and a deeper understanding of choices made out of routine are part of this surplus.

\subsection{Towards a Circular Economy Business Model}

A business model aimed at sustainability by means of re-use, remanufacturing and recycling depends on products that are returned either to a manufacturer or specialized third parties. The business model needs to have ownership by the manufacturer as a starting point to close material loops. Ultimately, customers will not buy new furniture, but they only pay for use, i.e., changing from ownership to performance-based payment models (e.g., Stahel 2010; Webster 2015; Lovins and Braungart 2013). To investigate a new circular business approach and simulate different circular based service scenarios for different customers and type of products, a dynamic modelling approach has been adopted (Groesser, Chapter "Complexity Management and System Dynamics Thinking" this book). The SD model supports enhancement of the decision-making process by the Gispen management team to develop, implement, and grow a new business model based on a circular economy (i.e., what kind of business model scenario might be successful within the model boundaries and assumptions). We used the software Vensim(C) (Ventana Systems, Inc., Harvard, Massachusetts) for the development of the simulation software. Vensim is able to simulate dynamic behaviour of systems that are impossible to analyse without appropriate simulation software, because they are unpredictable due to many influences and feedback interrelations. 


\subsubsection{Development Process}

An iterative approach has been used to quantitatively model Gispens' new business model. In the group model building sessions (Vennix 1996) the following steps were undertaken:

- Define the most important central KPI's, i.e., business objective variables, for Gispen. A shared definition of the business objective variables was determined to evaluate effects of different tested policies and scenarios. Hence, a common understanding of profit, total turnover, market share, etc. for current and future scenarios was formed.

- Define the relevant variables in the causal-context model (Groesser, Chapter "Complexity Management and System Dynamics Thinking" this book). A management science approach was used to structure discussions on input variables and important outcomes.

- Determine and quantify the relationships between central KPI's and variables in the model. Gispen management was frequently consulted to ensure that the model building proceeds in the right direction. Moreover, the Gispen management was involved in testing the model and evaluating the benefits for Gispen provided by the model. Gispen employees from sales and the financial department were involved to provide data on relevant business parameters which are used as initial values in the model. Macro-economic predictions at an EU level, existing GDP data, market trends for the office furniture market, standard values for cost and time to implement new business models structures and Gispen specific data such as annual reports and branch reports were incorporated (e.g., Cijfers and Trends Meubelindustrie 2013). Not all data required by the model (e.g., the quantitative relationship between product attractiveness and company profit) were known. Expert meetings were used to define best expert estimates for these assumptions in the model (Ford and Sterman 1997). Furthermore, several scenarios in terms of macro-economic conditions were taken into account (i.e., negative, neutral and positive trends) as well as a predefined bandwidth for variables with a high level of uncertainty. Furthermore, the scenario and policy variables with the highest impact on business performance as well as the bounds for the set-up of these variables were defined.

- The model was validated on the level of model structure and model behaviour (Groesser and Schwaninger 2012). The focus was on internal and external validity of the model, for instance, were all relationships correctly modelled and KPI's calculated in a correct manner, and concurrent validity, i.e., does the model give similar results for the model predictions and Gispen historical data.

A circular business scenario was modelled and evaluated. Within this business scenario, office furniture will be leased to an user (who will pay per month) and will get a financial incentive by Gispen after several years of use. In this model, Gispens' current, i.e. linear, as well as the new circular business model were both included (Fig. 2). 


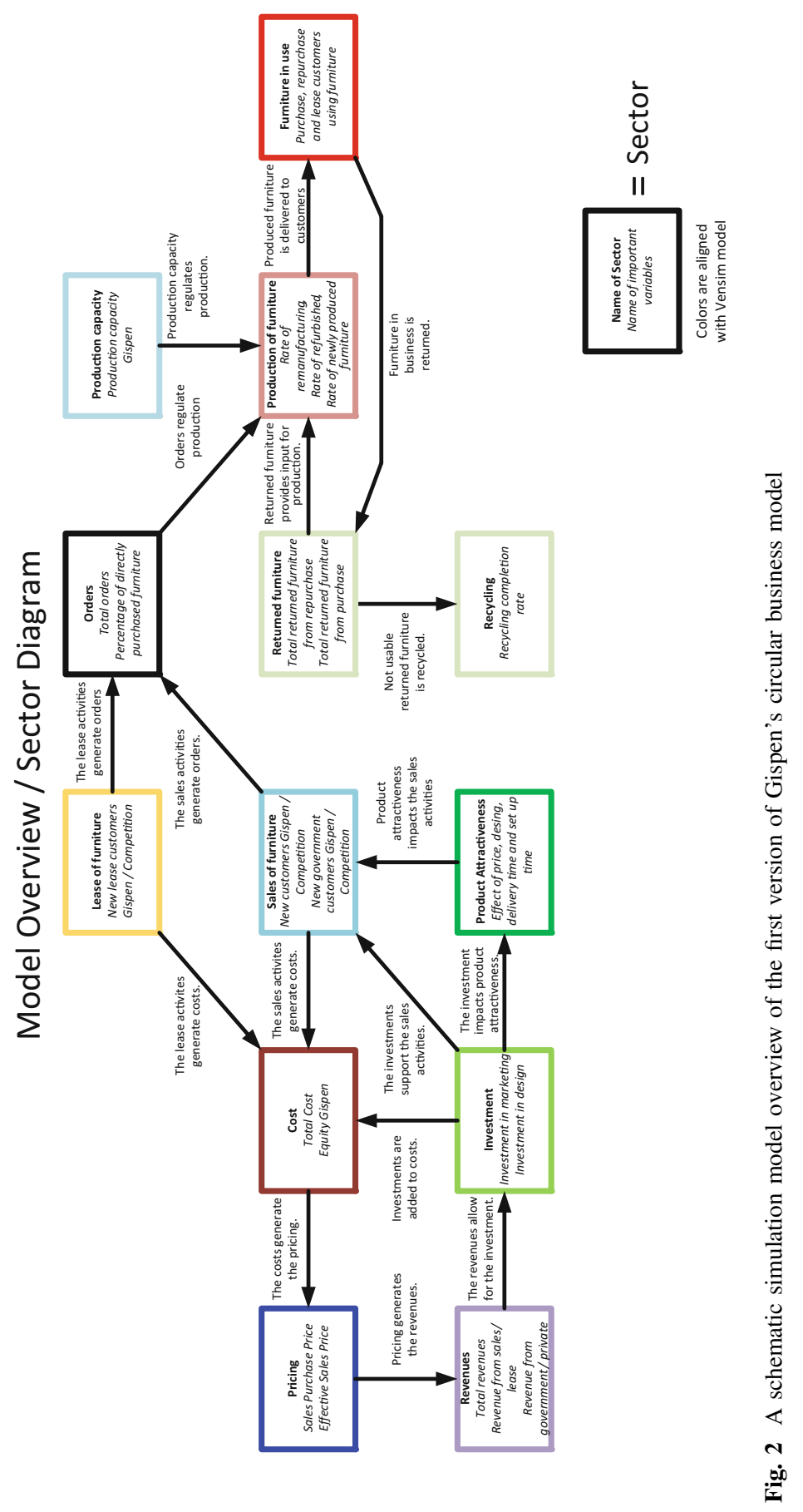


The main learnings from this model were summarized and included in a more simplified SD model to facilitate an easier understanding. Moreover, the simplified SD model has a narrower system boundary and focused only on the new business model (Fig. 3). Following the conclusions of the first model the new business model was treated as a separate business unit with no influence from running businesses, apart from some initial assumptions such as that Gispen already had a customer base. Different model development steps were undertaken to ensure a consistent model in which all relationships were modelled correctly and all KPI's were calculated in a correct manner. Moreover, the structure of the model has been discussed extensively in several workshops and the face validity of the behaviour of the model was evaluated (for validation see Chapter "Complexity Management and

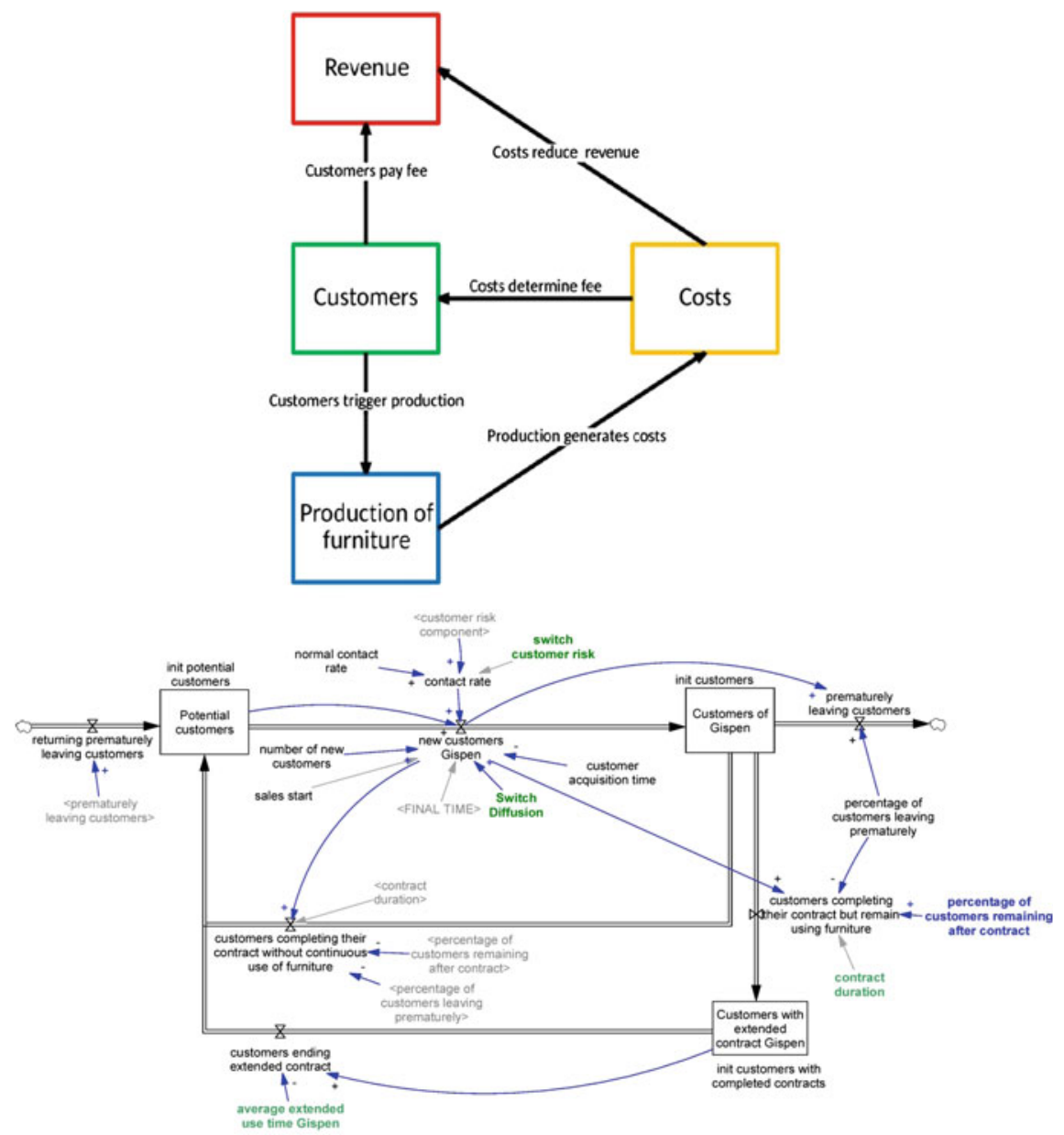

Fig. 3 High level overview of the final business simulation model (top) and a more detailed impression of a part of the SD model (bottom) 
System Dynamics Thinking"). The initial settings of the models parameters were checked and different scenarios evaluated to see its effects on the most important KPI Gispen was interested in: the break-even point.

\subsubsection{Results}

In this section, the most important outcomes of the simplified model are described. In the final version of the model, historical data of the current business model were used where reasonable. This model included three major loops, the loop of cash, the loop of customers, and the loop of products, i.e., furniture. These three loops were modelled only considering circular economy furniture and not making a difference between refurbished and remanufactured furniture and different types of customers, i.e., new or existing customers in different market segments. Cost structures were implemented in simple terms.

From the simulation model the following conclusions were drawn:

- The implementation of circular economy of assets with a long usage cycles generates long delays with high negative initial cash flows in a pay per use scenario. This leads to the conclusion that lease models, as we currently know and apply, are less usable to drive more sustainable use of products. Integration of service components and solutions to get through the 'first use' period needs to be considered in more detail as this causes a highly negative cash flow (Fig. 4). A possible option, among others, is the intensification of the use of products, i.e., stimulate multiple or serial use (Webster 2015; Stahel 2010). Another option that might be viable is upgrading existing Gispen products, as a service, at the customer site (i.e., move from production to services).

- The business model made it possible to simulate not only Gispen's internal processes, but also their interaction with market and competitors. This also allowed to focus on the adaptation of the market, competitors and own organization, pinpointing the uncertainty of the adaptation speed that is a critical point in the model. Figure 5 shows the accumulated profit for the base run and two alternative scenarios. The base run is simulated with an adoption fraction of 0.008 , meaning that 8 contacts out of 1,000 between clients result in a successful client acquisition and an effectiveness of marketing of 0.00025 , meaning that 25 out of 100,000 potential clients are attracted every month as new customers. To show the effects of different adaptation speeds the scenarios 'comblow' and 'combhigh' have been created with the settings of 0.004 for adoption fraction and 0.000125 for effectiveness of marketing in the 'comblow' run and 0.012 and 0.0005 for 'combhigh' respectively. 'Comblow' therefore simulates the effects, if the adoption is low in both marketing and word of mouth while 'combhigh' simulates when the new business model is embraced more quickly by the customers. In terms of effects the breakeven point for the business model in the scenarios are 109 (comblow), 147 (base) and 150 (combhigh). Low adoption rates have therefore a positive effect on the time to breakeven, mainly due to the 


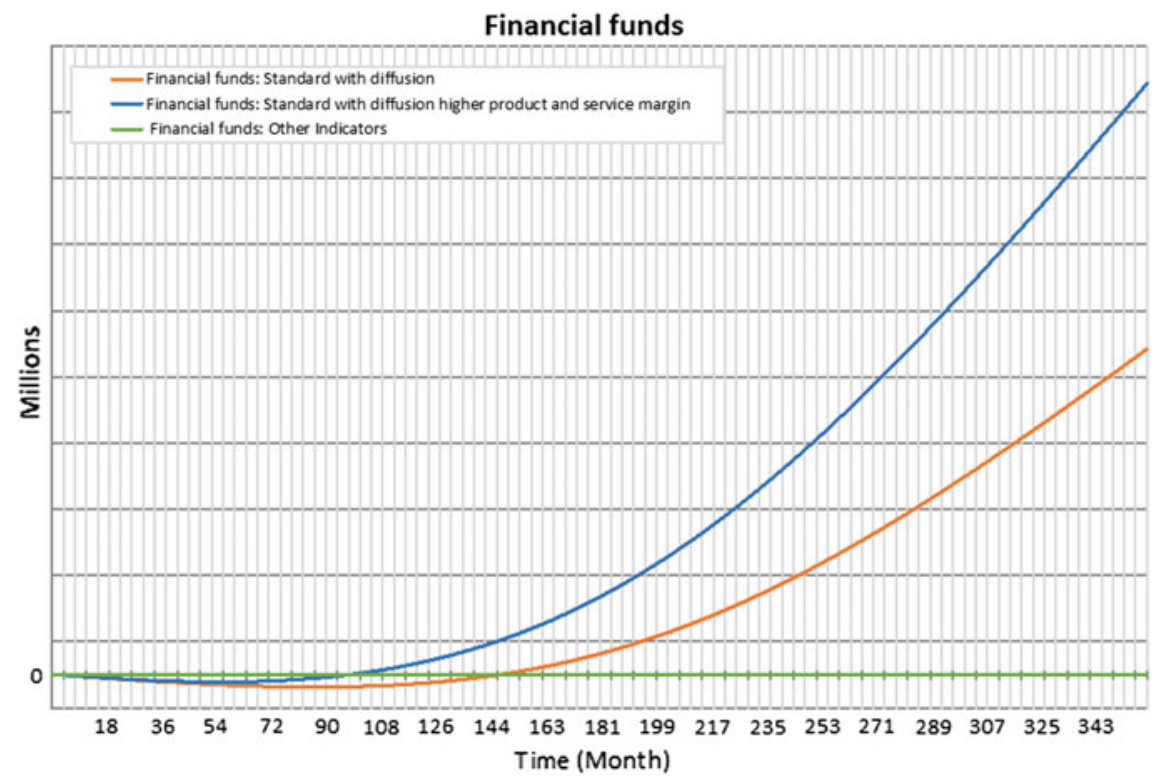

Fig. 4 Example of system dynamics simulation outcome: two scenarios of how financial funds develop over time given different assumptions for the product and service margins

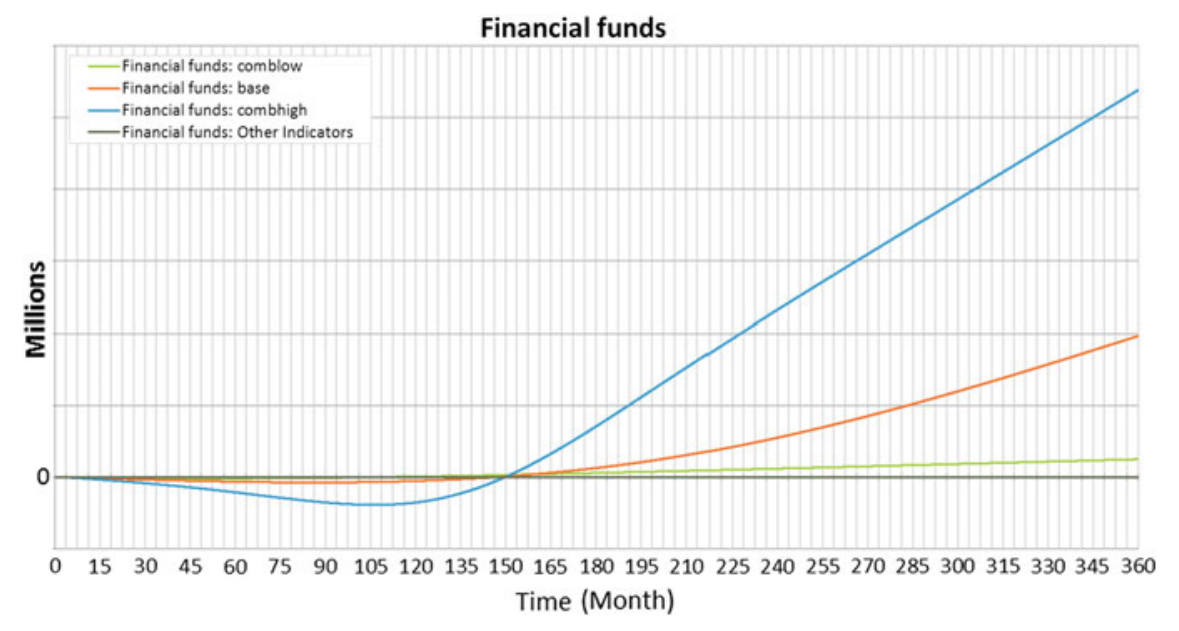

Fig. 5 Accumulated profit for Gispen for different adaptation rates 
fact that investments are low. The challenge for the new business model is that the costs arise at the beginning of a customer contact (production costs), while the flow of revenues is distributed over the entire duration of the contract (breakeven of an individual contract is between 39 and 40 months on a 60 months contract). This is illustrated by the scenario 'combhigh' where many customers are attracted quickly. Once the new business model is implemented however, the higher rate of turnover of furniture (and thus input for refurbishment) also makes the financial funds grow the fastest.

- Main added value of dynamic modelling is the deeper understanding of the mechanisms simulated. The method forces the user to provide well-founded reasoning and data to make the model reliable.

\subsubsection{Upgrade as a Service}

In essence the goal is to waste as little resources as possible. To do so one option is to upgrade or remanufacture existing, client owned furniture. A service is provided by the manufacturer and resources remain at the highest utility value. In practise the process starts with an inventory of the furniture in use and an inventory of the desired requirements for this furniture. These two are matched and additional services are executed, if possible on the customer site to keep transport to a minimum. A proven concept so far is to reuse desks and remanufacture the pieces to 'as new' desks. Visually the remade desk cannot be set apart from newly produced, and warranties are applicable for the remade desk. Since there is no shift of ownership and most of the existing materials are reused, the remade desk is considered a service. Which in turn can be embedded in a pay per use model. Even though the costs are still incurred at one moment in time, whereas the service is payed over a period of time a combination of tools can prevent the extreme dip in cash flow as described above. If at initial delivery a service package, including maintenance and upgrades, is agreed a more stable cash flow can be realized

\subsubsection{Benefits of System Dynamics Modelling}

The current simulation model concentrates on the objectives of Gispen but could also be used as an illustration of added value of business or process modelling for other companies. The development process of a model itself forces participants to create a shared vision/idea of the new business concept. Moreover, it organizes thoughts, concepts and ideas and how these interrelate. To create commitment of management or stakeholders they should be involved in this development. Furthermore, this development process leads to a better understanding of all related aspects and their relationships. A first simulation of strategies ('trial and error') can be done in the model before implementation in the real world takes place. Thereby more successful and durable changes in any business model are supported. 


\subsubsection{Lessons Learned}

The lessons learned of the application of system dynamics modelling in supporting the exploration of alternative business models are summarized below.

- To simulate the relevant aspect of reality in detail, a quite comprehensive and thus complex model was developed. The quantification of the resulting relationships is time demanding and challenging, but results in a detailed understanding of the mechanisms involved. After the detailed understanding of relevant system, the extensive simulation model was simplified. The second simulation model focusses exclusively on the new circular economy business model of Gispen. By using this model with lower complexity and details, it was possible to provide relevant information to the management team enabling them to obtain the insights for their decision making. In other words, only after the detailed model was developed it was possible to focus on the relevant mechanisms in the simplified model which then provided better insights in the relevant developments of the business model with concrete results. It is often, not always, beneficial to develop a larger model first to be able to evaluate what aspects of a situation are actually necessary.

- It was possible to demonstrate the robustness of the model through many extreme condition tests and through the consistency of the units of measure. To have a more practical discussion on the feasibility of circular business model scenarios, it is useful to provide detailed information for decision making. A dashboard which shows the assumptions in the model and visualize the input and output could be a helpful means to enable even deeper discussions.

- In certain cases, to show to the management a certain trend, the timescale assumption was set to 2050. This was necessary since the delay times (use periods of the furniture products) in the modelled business system are relatively large and hence, changes in the underlying business model can only be seen, for instance, after several iterations of remanufacturing of furniture. A time horizon of 2050 is long, given that the time horizon for decision-making is regularly much shorter. After determining a trend by using the model with the long time horizon, it would be useful to then relate again to a timescale of 7-10 years. Disparities in business dynamics and decision dynamics are challenges which the SD model could demonstrate. But given the dominant paradigms for decision makers and the strong competition in the furniture industry, the SD model could not influence the decision making processes regarding the time expectations.

- The model is a means to evaluate the business potential. Such simulation models are used a few times during a year when the top management team reflects about its current corporate strategy.

- Group model building turned out to be successful in face-to-face meetings (Groesser, Chapter "Complexity Management and System Dynamics Thinking"). Misunderstandings or decisions taken were easier to understand in these meetings compared to virtual meetings or discussions. 
- Involvement of different stakeholders, among others, management representatives during the development process and critical decisions on assumptions of the model will require time, but at least the major and important conclusions of every development step should be evaluated by management. Moreover, the assumptions taken during development process should be shortly described and presented to management.

\subsection{Creating a Design Framework for Circular Economy Office Furniture}

Gispen has a high level of customization (i.e., Engineer To Order projects). In the near future Gispen wants to keep this high level of customization in their products, but at the same time a modular product design should allow easy (dis)assembly and adaptability. In order to do so, design guidelines and circular requirements for product design, re-design and remanufacturing are necessary. These guidelines are part of a Circular Economy Design Framework (hereinafter Circular Framework, Fig. 6). The ultimate goals to achieve with support of the Circular Framework are (1) no waste or pollution during the entire life cycle (2) $100 \%$ re-use of products, modules and parts, (3) no use of energy from non-renewable resources for producing products or the use of products itself; (4) no use of virgin materials and (5) maintain the highest possible value of the product during the product lifetime and maximisation of product lifetime itself.

The Circular Framework provides an approach including a checklist to sustainable design and aims to support designers and R\&D officers within Gispen to develop circular office furniture. Moreover, this approach will support Gispen to

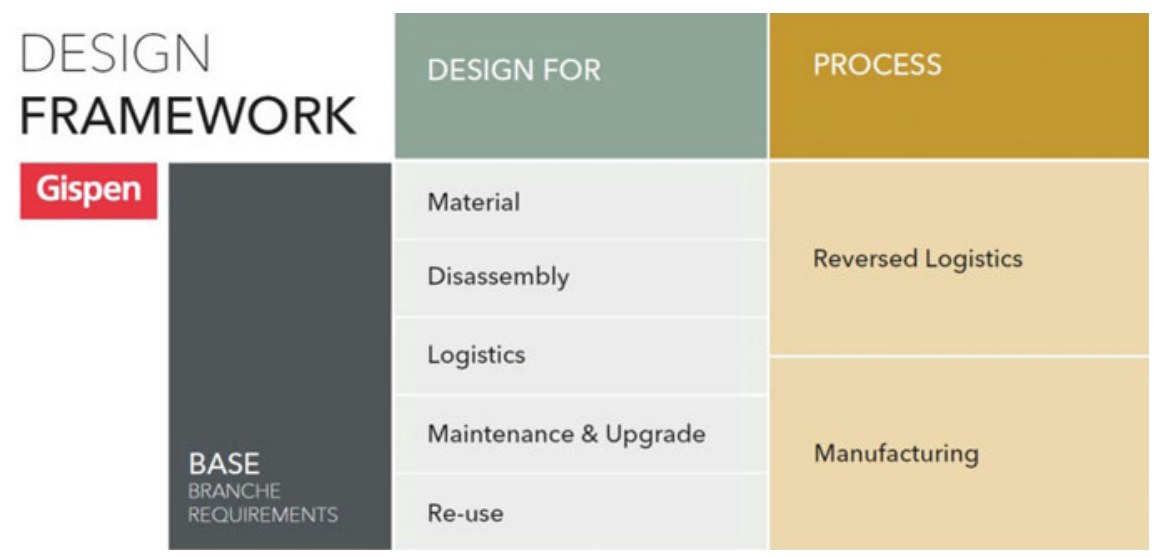

Fig. 6 The Gispen circular economy design framework 
adapt, by upgrading or retrofitting the product at the customer site or remanufacturing at the factory floor, in order to prolong the lifespan of the product and to meet the changing end-user needs. The checklist is based on some of the design principles described elsewhere in this book (Van Rhijn, Chapter "Fostering a Community of Practice for Industrial Processes" this book). All due to improvement of product design, more sustainable actions can be taken in the future. In other words, the lifespan of products and modules can be more easily prolonged. The initial cost trade-off is not incorporated in the Framework which is purely aimed at product design.

Sustainable design choices need to be well-founded. Generally accepted are LCA tools to calculate environmental impact. However, traditionally these tools have a take-make-dispose scenario. Insights in reuse, remanufacturing and the impacts thereof is needed. So the traditional LCA tool needs to be upgraded including new closed-loop scenarios, according to the circular economy concept. Besides a checklist, a Circular Life Cycle Analysis tool (C-LCA) is part of the Circular Framework. The background of this methodology has extensively been described (Pajula, Chapter "Virtual Reality and 3D Imaging to Support Collaborative Decision Making for Adaptation of Long-Life Assets" in this book). This tool aims to support product development and is based on the quantitative LCA methodology (Fig. 9). Besides product development departments, sales representatives should be able to show the effects of a particular circular scenario (e.g., sell, repurchase, and lease back) on environmental impact for different kinds of furniture, materials, and processes. Moreover, the combination of qualitative design requirements and quantitative LCA calculations provide an in-depth product evaluation to support the transition to a more closed-loop system.

\subsubsection{Development Process of the Circular Framework and C-LCA Methodology}

An iterative and participatory design (e.g., Douglas and Namioka 1993) approach was used to create the Circular Framework Checklist and C-LCA methodology. All stakeholders (sales, marketing, and R\&D employees) were actively involved in this process. The major steps for the framework and C-LCA development are described below:

- In a first stage, interviews were conducted to collect requirements from different company discipline perspectives.

- A conceptual design of both tools, based on existing methodologies and literature, end-user requirements and experts, has been created.

- This first concept of the tool has been presented to all stakeholders and validated. For example in the C-LCA, the information included in the database and its level of detail has intensively been discussed and finally a consensus has been reached. Furthermore, the degrees of freedom at the scenario definition stage were determined as well as the dashboard information shown to customers (by 
sales and marketing representative) and R\&D to support design decisions. For the framework major topics concerning product design were discussed as well as the level of detail of the framework.

- Several prototypes have iteratively been tested and evaluated by the company. Typical products were evaluated using several linear and circular life cycle scenarios. Feedback on user interfaces, level of detail and usability of the databases was collected by the development team to improve the final versions of the tools.

- A final version of the tool has been presented to all stakeholders.

The iterative, participatory development approach for these tools was particular useful for several reasons. Firstly, including stakeholders created a shared view on how the tools are going to be used and underline the benefits of the tools for this particular interest group. Secondly, participation required input from all stakeholders and thereby different perspectives. By providing input it becomes clear if and for what reason there is resistance regarding the new approach.

\subsubsection{Results-Checklist}

The Circular Framework contains a checklist for circular product design that results in a circularity score. Availability of design and process information, were the major requirements for the checklist. From a practical perspective, the time spend on the assessment of a product design with the checklist is crucial and should therefore be limited.

Office furniture is subject to various regulatory requirements aimed at health and safety of the products and the office environment (e.g., NEN-EN-1335-2 2009). These requirements remain 'intact'. Moreover, regulatory requirements are always fulfilled and are therefore not part of the final circularity score. The DESIGN block contains design rules and guidelines that are related to product design principles, clustered to main topics (e.g., re-use or maintenance). The PROCESS block contains all principles related to process a product. Each topic in both blocks contains various questions to provide an overall (single) score for a product. Questions in the checklist should simply be answered by clicking $(1)=$ 'Yes' or $(0)=$ 'No'. A clear definition for each aspect in the Circular Framework was determined and has been presented in Table 1.

To rank the different design and process aspects in the design checklist the 'in pairs equations' method (e.g., van Dieën and Hildebrandt 1991) has been applied. All predefined aspects were presented in pairs to experts inside and outside the company. They were asked to indicate which factor in each pair contributes most to a circular product design. Using these scores, frequency proportions and z-values (relative position with regard to the average) were calculated. The z-values were subsequently converted to calibration units, using a standard conversion table (Swanborn 1982) and finally to weight factors. 
Table 1 Definition of framework aspects and typical questions included in the circular framework checklist

\begin{tabular}{|c|c|c|}
\hline Framework aspect & Definition & Typical statement in the checklist \\
\hline Design—re-use & $\begin{array}{l}\text { Re-use of products, parts or } \\
\text { components for any (other) } \\
\text { purpose after a certain use period } \\
\text { instead of breaking them down } \\
\text { into raw materials. In a } \\
\text { closed-loop system maximisation } \\
\text { of reuse requires high quality and } \\
\text { flexibility as supported by design } \\
\text { criteria for product modularity }\end{array}$ & $\begin{array}{l}\text { Each product module has more } \\
\text { than one functionality and in case } \\
\text { of reuse a secondary functionality } \\
\text { is available }\end{array}$ \\
\hline \multirow[t]{2}{*}{$\begin{array}{l}\text { Design- } \\
\text { maintenance and } \\
\text { upgrade }\end{array}$} & $\begin{array}{l}\text { Maintenance of products, by } \\
\text { taking care of products through } \\
\text { (un)scheduled maintenance } \\
\text { activities on a regular basis, will } \\
\text { extend the product lifetime and } \\
\text { retain the product's value }\end{array}$ & \multirow[t]{2}{*}{$\begin{array}{l}\text { Product modules or components } \\
\text { could be replaced or exchanged } \\
\text { by one person within } 10 \mathrm{~min} \\
\text { without damaging other parts } \\
\text { through the use of dismountable } \\
\text { connections }\end{array}$} \\
\hline & $\begin{array}{l}\text { Upgrading a product, by adding } \\
\text { or removing parts from the } \\
\text { original product leads to a } \\
\text { functional or aesthetic } \\
\text { improvement of the product } \\
\text { without replacing the product as a } \\
\text { whole and thereby extends the } \\
\text { product lifetime }\end{array}$ & \\
\hline Design—logistics & $\begin{array}{l}\text { By taking into account product } \\
\text { packaging and product design } \\
\text { itself, volume, weight, waste, etc. } \\
\text { will be reduced and thereby } \\
\text { environmental impact and } \\
\text { product damage will decrease } \\
\text { during the transportation of } \\
\text { products }\end{array}$ & $\begin{array}{l}\text { The product has been designed to } \\
\text { allow flat packed or nested } \\
\text { transportation without increasing } \\
\text { the risk of product damage during } \\
\text { transportation or (un)packing } \\
\text { activities }\end{array}$ \\
\hline Design-material & $\begin{array}{l}\text { In order to create a closed-loop } \\
\text { system material waste does not } \\
\text { exist. Design choices of materials } \\
\text { are based on the ability to re-use } \\
\text { materials with minimal energy, } \\
\text { use of renewable resources and } \\
\text { use of non-toxic materials }\end{array}$ & $\begin{array}{l}\text { If available, recycled materials } \\
\text { have been used to produce a } \\
\text { product }\end{array}$ \\
\hline $\begin{array}{l}\text { Design- } \\
\text { disassembly }\end{array}$ & $\begin{array}{l}\text { Products are designed for taking } \\
\text { apart (disassembly) complex } \\
\text { products into interchangeable } \\
\text { modules, parts or components to } \\
\text { keep materials at their highest } \\
\text { utility and value. In a closed-loop } \\
\text { system products should be } \\
\text { designed for effective } \\
\text { disassembly without losing value } \\
\text { in materials, energy and labour }\end{array}$ & $\begin{array}{l}\text { If necessary, every product } \\
\text { module could be disassembled } \\
\text { into individual reusable } \\
\text { components }\end{array}$ \\
\hline
\end{tabular}


Table 1 (continued)

\begin{tabular}{l|l|l}
\hline Framework aspect & Definition & Typical statement in the checklist \\
\hline $\begin{array}{l}\text { Process- } \\
\text { manufacturing }\end{array}$ & $\begin{array}{l}\text { A closed-loop system should } \\
\text { avoid any consumption during } \\
\text { the manufacturing process. } \\
\text { Manufacturing energy must come } \\
\text { from renewable source }\end{array}$ & $\begin{array}{l}\text { Residual material and waste } \\
\text { during (re)manufacturing will be } \\
\text { collected, separated and recycled }\end{array}$ \\
\hline $\begin{array}{l}\text { Process- } \\
\text { (reversed) logistics }\end{array}$ & $\begin{array}{l}\text { The environmental impact of the } \\
\text { supply of materials and } \\
\text { transportation of products has } \\
\text { been minimized by optimizing } \\
\text { modes of transportation, strong } \\
\text { collaboration with suppliers, local } \\
\text { sourcing of materials and local } \\
\text { (re)manufacturing and recycling } \\
\text { of products }\end{array}$ & $\begin{array}{l}\text { Suppliers deliver parts, } \\
\text { components or modules in } \\
\text { reusable packages which are in } \\
\text { proportion to the size of the }\end{array}$ \\
\hline
\end{tabular}

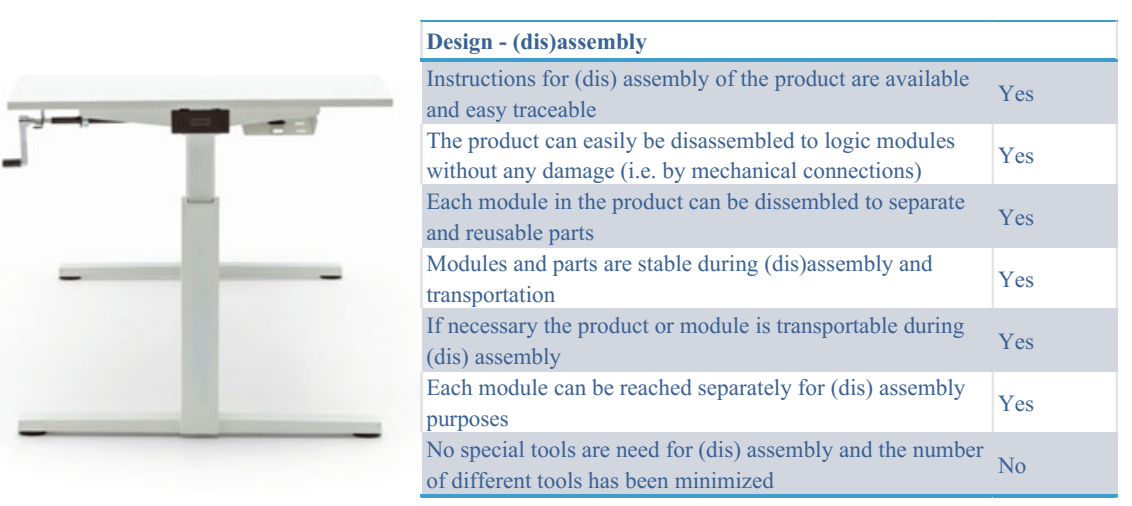

Fig. 7 Product of Gispen (left) and checklist scores for some of the (dis)assembly questions

As mentioned in the development approach, by means of several iterations the checklist was tested and adjusted. During this development process the checklist has been used to evaluate several product designs. An example of an assessment has been presented above for one of Gispen's typical office desks (Fig. 7). For this office desk, which was not specifically designed for circular use, about $40 \%$ of the questions were answered positive. Using the checklist stimulated a better understanding of design choices and their influence in the circular product life cycle, awareness of the circularity levels of Gispens current products and supported a push towards more creative solutions. A circular product design as shown in Fig. 8 about $65 \%$ of the questions were answered positive. 


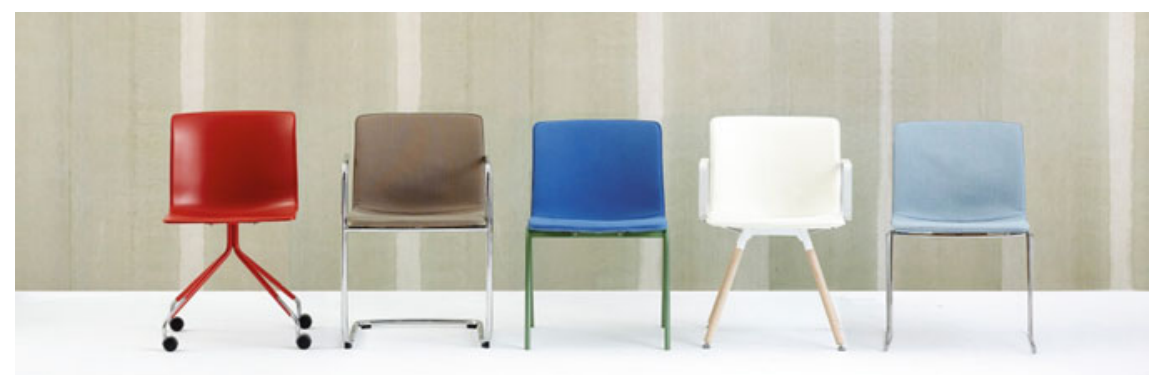

Fig. 8 Nomi, a highly modular seating system. Upgrades and visual changes are easy due to the flexible design and removable upholstery

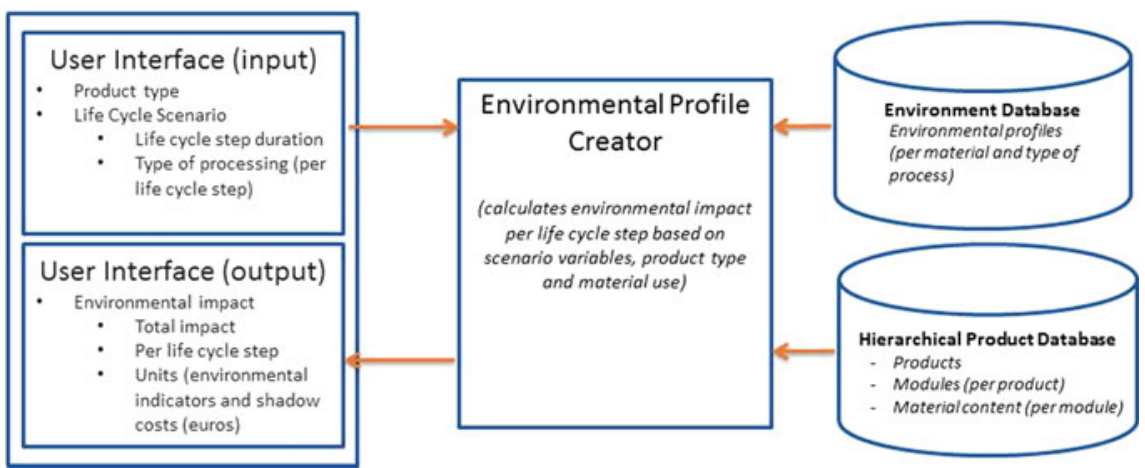

Fig. 9 A schematic representation of the CLCA methodology to calculate environmental impact of circular product life cycle scenarios

\subsubsection{Results-C-LCA}

The C-LCA tool is able to calculate environmental impact of an industrial product for the entire life cycle including closed-loop thinking (circular economy). A high level representation of the C-LCA methodology has been shown in Fig. 9.

The tool contains two databases:

1. A product definition database which contains relevant product characteristics. Product data are structured hierarchically; products are divided in modules, product modules contain information on material composition (type of material and the amount) and the required (re)manufacturing processes and transport for this product module.

2. An environmental profile database which contains the environmental impact (e.g. climate change) of materials (e.g. steel but also bio-based materials) and manufacturing (e.g., bending, final assembly), maintenance (e.g., cleaning) and transportation processes. 
Based on the selected product type, the selected life cycle scenario (e.g. 'linear': Take-Make_Dispose or 'Circular Refurbishment': Take - Make-Use-Clean and repair-Reuse-Remake-Reuse-Dispose) and life cycle duration, the database information is used to calculate environmental profiles for the entire product life cycle. The total impact (expressed in, e.g., euros and $\mathrm{kg} \mathrm{CO}_{2}$ ) for a (circular) product life cycle scenario is calculated and presented to the user. Sales representatives are able to show the effects of different kinds of furniture and materials, and a particular use scenario (e.g. sell, re-purchase and lease back) on environmental impact. Engineers could easily compare the environmental impact of their design decisions and thereby optimise product design from a sustainability perspective.

The C-LCA tool has been used to describe various circular scenarios. For example, for a particular client of Gispen the estimated benefits of reuse were different based on the selected decision criteria. These decisions combined various factors (1) sustainability (2) aesthetic value of the office environment (interior design requirements) and (3) costs. By creating two scenarios where the aesthetic value was similar we were able to demonstrate that a higher percentage of reuse was the most efficient choice, i.e. sustainable wise as well as cost efficiently. Furthermore, by discussing the data it created the opportunity to collaborate on planning and disassembly issues in order to avoid unnecessary transport and thereby save additional costs. C-LCA calculations where performed for the product shown in Fig. 10. It is a normal desk with a table top made out of steel.

As can be seen in the results of the calculation (Fig. 11, right), opting for a refurbishment scenario saves $1.3 \mathrm{~kg} \mathrm{CO}_{2}$ emission per year during the total lifespan of the product, here set at 12 years. As is shown in the left graph in Fig. 11, reuse outweighs virgin production vastly. In the right graph of Fig. 11 benefits and additional contribution to the emission of $\mathrm{CO}_{2}$ is presented. Except logistics, as

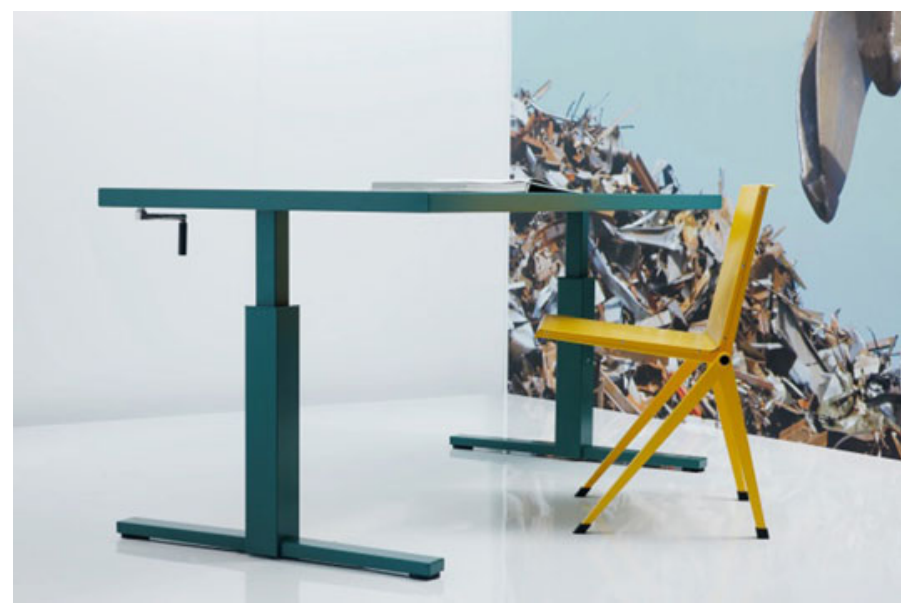

Fig. 10 Gispen TM Steel top 


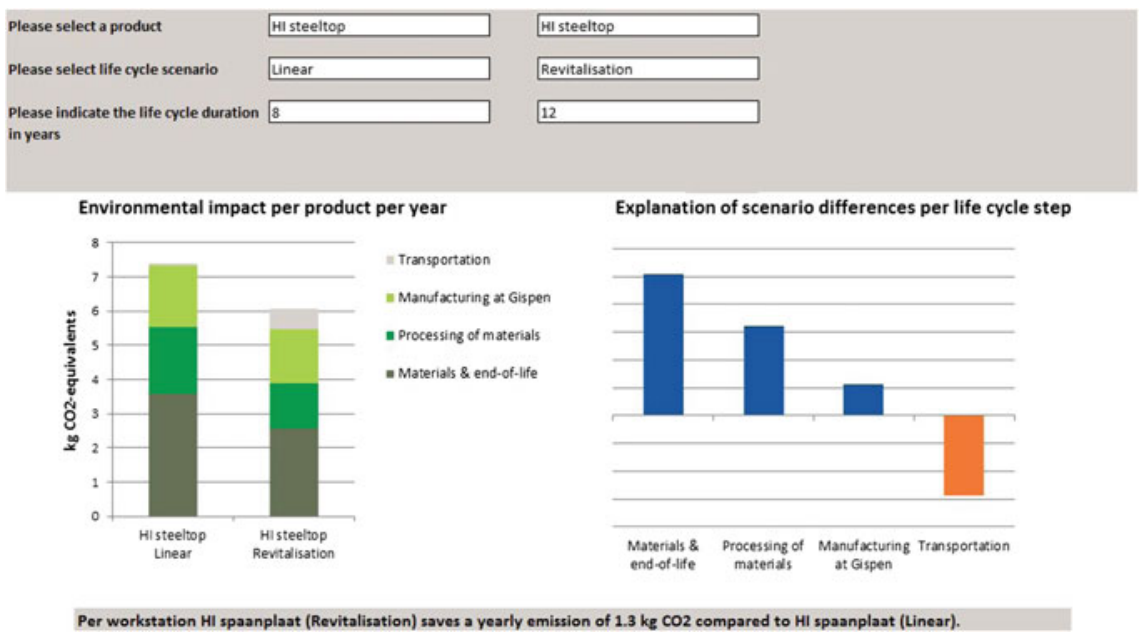

Fig. 11 Outcomes of the C-LCA calculations for a linear as well as revitalization scenario (bottom)

reversed logistics were part of this circular scenario, reuse reduces $\mathrm{CO}_{2}$ emission compared to a linear scenario. Upgrading on site was the most optimal form of product-life expansion in this particular customer case.

\subsubsection{Benefits of the Circular Framework and the C-LCA}

By using the Circular Framework, Gispen could show customers the degree of circularity of their products and the effects of several product life cycle scenarios (i.e., linear vs. circular). A more quantified effect of, for example, design choices in material or packaging on the environmental impact could be visualized. Using the Circular Framework thereby supports a decision making of Gispen and their customers. Furthermore, the framework and C-LCA create awareness of choice of material and process impact amongst designers, R\&D and sales employees. The mission and vision of Gispen are translated in realistic objectives and the framework has been aligned to these objectives. Thereby, it contributes to the development of a circular product portfolio.

The framework provides insight in the degree of adaptation to circular principles. By filling out the checklist for each product design, and thereby creating a total score for the product, it is possible to compare one product versus another. This circular product score provides information to monitor progress on circular design and adjust whenever necessary. The checklist is a first attempt to create a tool which is easy to use for designers and on the other hand is covering the broad topics of design for circularity. 


\subsubsection{Lessons Learned}

- Involvement of different end-users during the development process requires time and effort but improves the understanding of the methodology and thereby creates the opportunity to deal with resistance against the new methodology. Moreover, user interfaces, are adapted to the different user needs and thereby usability has been improved. However, presenting the data in a way that is easily understood by the various user groups and has the right level of detail is still challenging.

- The Circular Framework checklist and C-LCA are just tools. If these tools are not adequately implemented in current design and sales processes within the company, the benefits of both tools will be marginal.

- Traditionally design for a particular discipline is built up on the creation of rules to be applied during product design in the product development department, or in concurrent engineering between departments within or outside the company. Designing for a closed-loop system is designing for future use, whilst use might change over time. Upgrading a product during its life time and usage will require the product development function to get directly involved in the customer interface. Product development engineers can no longer expect to be given readymade.

- It might be concluded that both tools can be applied in other sectors and companies but the success of the tools will be based on the willingness to embrace the principles and company culture of a closed-loop system.

- In general the C-LCA methodology is fairly technical and detailed product information on materials and processing is needed to make any calculation.

- Maintenance or updating the C-LCA tool with new products, modules, materials and processes can only be done by a few employees of Gispen. A LCA expert outside the company is needed in case alternative materials (e.g., bio-based materials like bamboo, engineered wood), which are not included in the current database, will be used in product designs.

- The C-LCA methodology provides outcome parameters (e.g. environmental costs in euros or $\mathrm{CO}_{2}$ in $\mathrm{kg}$ ) which could easily be understood by non-expert users.

- The checklist questions have been based on existing literature (e.g., Boothroyd 1980) and if needed, adjusted according to expert opinions. To ensure a similar understanding and interpretation of checklist questions different disciplines have been involved. Nevertheless, in depth knowledge of the aim of questions is sometimes required to get correct answers. A clarification has been added to support the user and avoid misinterpretation. Training of users will be considered in case this seems insufficient.

- The checklist is a qualitative assessment with a limit number of design and process aspects to ensure a limited time effort from engineering perspective and easy understanding from a customer perspective. The checklist has not yet been validated and is a first step to show circularity aspects in furniture to customers. 


\section{Conclusion and Future Work}

Although the circular economy is a current issue, the industrial state-of-the-art is that still a limited number of manufactures have shown a shift towards a closed-loop business. Companies exploring these new strategies are primarily focused at servicing at their customers site and not on total efficient and cost effective reverse logistics, disassembly and remanufacturing strategies with their entire supply chain. Primary processes and supporting ICT systems are insufficient developed, neither is the use of alternative bio-based materials sufficiently developed to enable large scale exploitation. Gispen has successfully started working on circular economy projects. Simulated business model scenarios, among others, have been used to establish new business agreements with public and private companies in the Netherlands. To support awareness of designers and engineers the design methodologies will be implemented and updated in the near future. Furthermore, the circularity level of Gispen products can be transparently shown to potential customers by using the scores of the C-LCA and Circular Framework outcomes. By means of this data, customers can be informed by Gispen about the effect of their decisions and choices on product life cycle impact, business wise as well as from a sustainability perspective. A next step will be the transition from successful projects towards a closed-loop thinking company culture. Moreover, Gispen has identified additional needs and will continue the implementation of their circular economy strategy by the following developments in the near future:

- A furniture management system will be setup for monitoring product use and ageing at the customer site. Due to rapid technology developments, we now have access to a wide range of low-cost embedded microelectromechanical systems (e.g. accelerometers or gyroscopes). These sensor data could be useful to monitor product use (e.g., Cheng et al. 2013) and thereby support decision making to follow the best strategy for service and maintenance, disassembly, remanufacturing and recycling.

- To overcome the high labour costs caused by manual disassembly (Duflou et al. 2008), smart disassembly systems with operator ICT support for (manual) operations and semi-automated stations might be a direction for future developments. Moreover, the use of cognitive, vision-based robots for quality control of returned products (Vongbunyong et al. 2012) and for example the use of low-cost collaborative robots looks promising also for SME's.

- A decision support system for remanufacturing strategy on a component level incorporating quality assessment of remanufactured components and products. This would involve new policies based on remanufacturing, reversed supply chains and revenue and cost management fit for these flows.

- Further business model exploration by the development of incentive based methods of contracting, including financial incentives for a closed-loop system possibly within a linear accounting system. Ultimately, Gispen creates sensible alternatives from a financial, fiscal, and legal point of view to ensure closed-loop 
systems. This would need not only a pragmatic solution regarding incentives, but more general a systemic change.

- Development and use of new bio-based materials in office furniture. Finding materials that are fit for all the use requirements today, are renewable and of a stable supply. Nowadays, bio-based material is not of a fit quality and is unstable in supply which is devastating for high volume use.

\section{References}

Allwood, J. M., Ashby, M. F., Gutowski, T. G., \& Worrell, E. (2011). Material efficiency: A white paper. Resources, Conservation \& Recycling, 55, 362-381.

Boothroyd, G. (1980). Product design for assembly. Department of Mechanical Engineering, University of Massachusetts, Amherst.

CEPS (2014). The EU furniture market situation and a possible furniture products initiative. DG Enterprise and Industry.

Cheng, J., Zhou, B., Sundholm, M., \& Lukowicz, P. (2013). Smart chair: What can simple pressure sensors under the chairs' legs tell us about user activity? In UBICOMM 2013: The Seventh International Conference on Mobile Ubiquitous Computing, Systems, Services and Technologies (pp. 81-84).

Cijfers \& Trends Meubelindustrie. (2013). https://www.rabobankcijfersentrends.nl/index.cfm? action=branche\&branche $=$ Meubelindustrie

Communication from the Commission to the European Parliament, the council, the European economic and social committee and the committee of the regions (2015). Closing the loop-An EU action plan for the Circular Economy. http://eur-lex.europa.eu/legalcontent/EN/TXT/?uri= CELEX:52015DC0614

Department for Business, Innovations and Skills. (2012). Low carbon environmental goods and services.

Douglas, S., \& Namioka, A. (Eds.) (1993). Participatory design: Principles and practices. Boca Raton: CRC Press.

Duflou, J. R., Seliger, G., Kara, S., Umeda, Y., Ometto, A., \& Willems, B. (2008). Efficiency and feasibility of product disassembly: A case-based study. CIRP Annals-Manufacturing Technology, 57(2), 583-600.

Ellen MacArthur Foundation. (2013). Towards the circular economy. In: Economic and business rationale for an accelerated transition, Vol. 1. Ellen MacArthur Foundation. Available from: www.ellenmacarthurfoundation.org

Ford, D. N., \& Sterman, J. D. (1997). Expert knowledge elicitation to improve formal and mental models. System Dynamics Review, 14(3), 309-340.

Groesser, S. N., \& Schwaninger, M. (2012). Contributions to model validation: Hierarchy, process, and cessation. System Dynamics Review, 28(2), 157-181.

Innovatie Zuid. (2013). Hightech systemen en materialen: Remanufacturing.

Lovins, A. B., \& Braungart, M. (2013). A new dynamic - Effective business in a circular economy. Ellen MacArthur Foundation Publishing.

McKinsey. (2011). Resource revolution: meeting the world's energy, materials, food, and water needs. McKinsey Global Institute; McKinsey and Company Sustainability, Resource Productivity Practice. Available from: http://www.mckinsey.com/mgi

NEN-EN-1335-2. (2009). Office furniture-Office work chair-Part 2: Safety requirements.

Savaskan, R. C., Bhattacharya, S., \& Van Wassenhove, L. N. (2004). Closed-loop supply chain models with product remanufacturing. Management Science, 50(2), 239-252.

Stahel, W. R. (2010). Performance economy. Basingstoke: Palgrave MacMillan. 
Swanborn, P. G. (1982). Scale techniques. Amsterdam: Boom.

USITC. (2012). Remanufactured goods, overview US and global industries.

Vennix, J. A. M. (1996). Group model building: Facilitating team learning using system dynamics. Chichester: Wiley.

van Dieën, J. H., \& Hildebrandt, V. H. (1991). Het gebruik van weegfactoren in een ergonomische risicoanalyse. Tijdschrift Voor Ergonomie, 16, 15-24. (in Dutch).

Vink, P., Blok, M., Formanoy, M., De Korte, E., \& Groenesteijn, L. (2012). The effects of new ways of work in the Netherlands: National data and a case study. Work, 41(S1), 5081-5085.

Vongbunyong, S., Kara, S., \& Pagnucco, M. (2012). A framework for using cognitive robotics in disassembly automation. Leveraging technology for a sustainable world (pp. 173-178). Berlin, Heidelberg: Springer.

Vos, P., \& Van der Voordt, T. (2002). Tomorrow's office through today's eyes: Effects of office innovation in the working environment. Journal of Corporate Real Estate, 4, 48-65.

Webster, K. (2015). The circular economy - A wealth of flows. UK: Ellen Mc Arthur Foundation Publishing.

Open Access This chapter is licensed under the terms of the Creative Commons Attribution-NonCommercial 4.0 International License (http://creativecommons.org/licenses/by-nc/ $4.0 /)$, which permits any noncommercial use, sharing, adaptation, distribution and reproduction in any medium or format, as long as you give appropriate credit to the original author(s) and the source, provide a link to the Creative Commons license and indicate if changes were made.

The images or other third party material in this chapter are included in the chapter's Creative Commons license, unless indicated otherwise in a credit line to the material. If material is not included in the chapter's Creative Commons license and your intended use is not permitted by statutory regulation or exceeds the permitted use, you will need to obtain permission directly from the copyright holder.

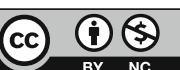

